\title{
Plant regeneration through somatic embryogenesis and synthetic seed production in Rumex vesicarius L. - A Potent medicinal herb
}

\author{
Nandini B.P. ${ }^{* 1}$, Sudarshana M. $\mathrm{S}^{2}$. and Rajashekar $\mathrm{N}^{3}$ \\ ${ }^{1,2,3}$ : Plant tissue Culture laboratory, Department of studies in Botany, Manasagangotri, University of Mysore, \\ Mysore -570006, Karnataka, India.
}

\begin{abstract}
Rumex vesicarius $L$. is an edible herb belonging to the family Polygonaceae. It has many important medicinal uses. Since there are no reports available on somatic embryogenesis and synthetic seed production in this potential medicinal herb, the present study is undertaken to optimize protocol for somatic embryogenesis and synthetic seed production from $R$. vesicarius $L$. Different explants of $R$. vesicarius were cultured for profuse callusing and regeneration on MS medium with different combinations of growth regulators. Somatic embryos were encapsulated and stored up to 60 days with five time intervals at two storage temperature, cold $\left(4^{\circ} \mathrm{C}\right)$ and room temperature. Embryogenic callus was obtained on MS medium supplemented with BAP (2 mg/l) and NAA $(0.5 \mathrm{mg} / \mathrm{l})$. Transfer of embryogenic callus on MS medium with $2 \mathrm{mg} / \mathrm{l} 2,4-D$ supplemented with $40 \%$ coconut milk, resulted in somatic embryos. Leaf derived callus when cultured on MS medium supplemented with BAP $(4 \mathrm{mg} / \mathrm{l})$, NAA $(1 \mathrm{mg} / \mathrm{l})$ developed multiple shoots, subsequently the excised shoot transferred on half strength MS with NAA $(1 \mathrm{mg} / \mathrm{L})$ induced rooting. Stored encapsulated somatic embryos were cultured on MS medium amended with BAP $2 \mathrm{mg} / \mathrm{l}$ and $N A A 0.5 \mathrm{mg} / \mathrm{l}$ for regeneration of plants. Cold temperature stored synthetic seed showed high rate of survivability compared to room temperature. The protocol developed in this study is simple and effective tool for mass propagation and conservation of Rumex vesicarius $L$.
\end{abstract}

Key words: Coconut milk, Multiple shoot, Regeneration, Somatic embryo.

\section{Introduction}

Rumex vesicarius $\mathrm{L}$. is a wild edible plant belonging to the family Polygonaceae. It has many important medicinal uses such as treatment of tumours, hepatic diseases, constipation, calcules, heart troubles, diseases of the spleen, hiccough, flatulence, asthma, bronchitis, dyspepsia, piles, scabies, leucoderma, toothache and nausea. The plant is also used as cooling, laxative, stomachic, analgesic, appetizer, diuretic, astringent, purgative, antispasmodic and antibacterial agents, to reduce biliary disorders and to control cholesterol levels. Seeds as antidote for scorpion venom and many other ailments. Dark green to brown and dark grey mordant free dyes can be obtained from the roots of R.vesicarius. ${ }^{[1,2,3]}$

$R$. vesicarius is propagated through seeds and the seeds are regarded as dormant. Low seed germination percentage $(20 \%)$ lessens its survivability. ${ }^{[4]}$ Continuous exploitation of this plant for various medicine preparations resulted in depletion of plant resources. Hence, the conservation of this valuable genotype is imperative. In vitro propagation is an important tool for conservation as it may provide complimentary conservation options for plant species with limited reproductive capacity ${ }^{[5]}$

Somatic embryogenesis provides an ideal experimental tool for investigation of plant differentiation as well as the large-scale production of plants. Somatic embryogenesis, has been reported in many medicinal plants such as Psoralea corylifolia ${ }^{[6]}$, cumin $^{[7]}$, rice ${ }^{[8]}$ etc. Encapsulation of somatic embryo or synthetic seed technology has been widely studied and is found to be applicable to several plant species including Allium sativa ${ }^{[9]}$, Daucus carota ${ }^{[10]}$, Adhatoda vesica ${ }^{[11]}$ etc. Since scanty reports are available on in vitro propagation of Rumex vesicarius, the present investigation was undertaken to develop an efficient plant regeneration system via somatic embryogenesis and to explore synthetic seed production in $R$. vesicarius.

\section{Materials and methods}

2.1 Plant material and culture conditions : Different explants were excised from stock plants of Rumex vesicarius L. cultivated in the Botanical Garden, Department of studies in Botany, University of Mysore. Explants were washed thoroughly in running tap water and washed with detergent teepol for $5 \mathrm{~min}$ and surface sterilised with $0.1 \%$ mercuric chloride for $2 \mathrm{~min}$. The disinfected explants are washed with sterile distilled water to remove traces of sterilant after each treatment. The Murashige and Skoog medium ${ }^{[12]}$ was fortified with $30 \mathrm{~g} / 1$ sucrose and gelled with $0.8 \%(\mathrm{w} / \mathrm{v})$ agar and the $\mathrm{pH}$ was adjusted to 5.8 . The media was steam sterilized in an autoclave under $15 \mathrm{psi}$ and $121^{\circ} \mathrm{C}$. All the cultures were incubated at $25 \pm 2^{\circ} \mathrm{c}$ with $16 / 8$ photoperoiod under white fluorescent tubes $\left(25 \mu \mathrm{mol} \mathrm{m}^{-2} \mathrm{~s}^{-1}\right)$. 
2.2 Callus induction: Different explants like leaf, petiole, node, internode, peduncle, flower bud etc...were tested for callus induction on MS supplemented with different concentrations of 2,4-D and NAA alone and in combination with BAP and Kinetin at different concentrations ranging from $0.5 \mathrm{mg} / 1$ to $4 \mathrm{mg} / \mathrm{l}$. MS medium supplemented with different concentrations of 2,4 D (0.5-2.5 mg/l) with coconut milk (10 to 60\%) are used for induction of somatic embryos.

2.3 Histological studies: For histological investigations, both soft calli and embryogenic calli were fixed in FAA (Formalin-acetic acid-ethanol, 5:5:95v/v) for $24 \mathrm{~h}$, dehydrated in graded series of alcohol and then embedded in paraffin wax as described by Johansen ${ }^{[13]}$. Serial sections $(11 \mu \mathrm{m}$ thick) were taken and stained with haematoxylin and mounted in DPX. Sections were observed and micrographed using a compound microscope

2.4 Synthetic seed production and germination: Somatic embryos at the torpedo stage were collected and suspended in a matrix of MS medium containing sodium alginate (2-4\%), dropped into $100 \mathrm{mM} \mathrm{CaCl}_{2}$ solution so as to encapsulate the whole embryo. The system is kept undisturbed for 30-40 minutes for proper bead formation. The beads were washed in sterile distilled water to remove traces of $\mathrm{CaCl}_{2}$ and placed on sterile filter paper to remove excess water. All these process were done aseptically. For study of temperature effects, regeneration potentiality of synthetic seed was evaluated after storage of cold and room temperature at various intervals of $0,15,30 \ldots \ldots . . .60$ days. After defined period of storage the synthetic seeds were cultured on MS medium supplemented with different concentrations of BAP and NAA for germination. Data were recorded on germination percentage.

2.5 Hardening : Well rooted plants derived from somatic embryos as well as synthetic seeds were taken out from the test tube, washed with water to remove the traces of agar and then transferred to small plastic pots containing garden soil and sand in the ratio 1:1. The cups were covered with transparent polythene bags (with 34 small holes) to retain humidity and maintained at $22 \pm 2^{\circ} \mathrm{C}$ with $16 \mathrm{~h}$ photo period for two weeks in the culture room. The plantlets were nourished using quarter strength MS nutrient solution on alternate days for two week. The cups were transferred to green house for next two weeks and then transferred to field conditions

2.6 Statistical analysis: The experimental design were repeated four times at three time intervals. The obtained data were subjected to analysis of variance and the means were compared with Tukey's studentized range tests using SPSS 10.1 ver package 14.

\section{Results}

\subsection{Callus induction, somatic embryogenesis and regeneration of plantlets}

In the present investigation, explants like node (Fig 1 a), leaf (Fig 1 b), internode (Fig 1 c), peduncle (Fig 1d) etc., were tested for callus induction on different types of media like Murashige and Skoog medium, Gamborgs medium, Whites medium etc supplemented with different concentration and combinations of plant growth regulators (PGRs). The role of PGRs- NAA, 2,4-D (individual), BAP+NAA and 2,4-D+Kn (combination), on callusing for the explants used is tabulated (Table 1). Among the tested explants, profuse callusing was achieved from leaf explants on MS medium supplemented with 2,4-D (individual) and BAP+NAA (combination). However the morphogenic response of the callus varied, type I soft and creamish and type II embryogenic with greenish yellow nodule.

Type II embryogenic calli were subcultured on MS basal (hormone free media) and MS medium supplemented with 2,4-D (2 mg/l) along with five concentrations $(10,20,30,40$ and 50\%) of coconut milk. Embryogenic calli failed to transform into somatic embryo on basal media, whereas on MS medium with 2,4-D and coconut milk showed maximum conversion frequency (Fig e,f). Somatic embryo formation increased with increase in concentration of coconut milk up to $40 \%$ with 2,4-D (2 mg/l) (Graph 1). Various developmental stage of somatic embryo viz., globular (Fig 1g), heart shaped (Fig 1h), torpedo (Fig 1i) and cotyledonary stage (Fig 1j) were observed within three weeks. These somatic embryos were subcultured on half strength MS basal medium and MS supplemented with BAP (3 mg/l) and NAA $(0.5 \mathrm{mg} / \mathrm{l})$ showed rhizogenesis (Fig $1 \mathrm{k})$ and complete regeneration of plantlets respectively (Fig 11).

Multiple shoots were formed from embryogenic calli, when subcultured on MS medium supplemented with BAP $4 \mathrm{mg} / 1$ and NAA $1 \mathrm{mg} / \mathrm{l}$ (Fig 2e) and elongated on the same medium (Fig 2f). Further the multiple shoots were excised and subcultured for rooting on MS medium supplemented with NAA(1 mg/l), IBA $(0.5$ $\mathrm{mg} / \mathrm{l}$ ), IAA $(0.5 \mathrm{mg} / \mathrm{l})$. Profuse rooting was observed on MS with auxin NAA (Fig $2 \mathrm{~g}$ ). Rooted plants are transferred to small plastic pots (Fig 2h) and acclimatized (Fig 2k).

\subsection{Histology of embryogenic calli and synthetic seed production}

Cross section of type I callus ( 15 days old) showed irregular shaped cells, which were highly vacuolated without nuclei (Fig 2a) and type II callus are characterized by small aggregates of cell with prominent nucleus(Fig 2b). The histological section of type II callus showed developmental stages such as globular (Fig 2 c), shoot differentiated primordial leaf stage(Fig $2 \mathrm{~d}$ ) etc. 
The torpedo shaped somatic embryo were chosen for encapsulation. The matrix of encapsulate - alginate (2,3 and $4 \%$ concentration) in $\mathrm{CaCl}_{2}$ ( 100 and $125 \mathrm{mM}$ concentration) were left for 45 minutes for complexation (Fig 1i). After complexation, the synthetic seeds were germinated on MS medium supplemented with BAP (2 mg/l) and NAA $(0.5 \mathrm{mg} / \mathrm{l})$ (Fig $1 \mathrm{j})$. The data of germinability of stored synthetic seed were recorded and presented in the Table-2. The germinability of stored synthetic seed increased up to 45 days and declined in cold storage whereas there was no much difference in room storage. Further synthetic seeds were tested for time taken to protrude out and percent germination was recorded and tabulated (Table 3). From the table-2, it is evident that lower the concentration of alginate shows higher rate of germination recorded on MS medium supplemented with $\operatorname{BAP}(2 \mathrm{Mg} / 1)$ and $\mathrm{NAA}(0.5 \mathrm{Mg} / 1)$. On the other hand, two sets of synthetic seeds were stored at cold storage $\left(4^{\circ} \mathrm{C}\right)$ and room temperature $\left(21 \pm 2^{\circ} \mathrm{C}\right)$ with five storage time interval i.e $0,15,30,45$ and 60 days. The ex-agar plantlets derived from somatic embryos as well as synthetic seeds were taken out from the test tube, transferred to small plastic pots for hardening and then to green house conditions and finally to field conditions. Hardened and acclimatized plants were true to type in nature.

\section{Discussion}

In vitro studies provide a platform to multiply, conserve and make the plant material to be available throughout the year for further usage and research studies. In the previous studies, the use of 2,4-D either alone or in combination with other plant growth regulators induced profuse callusing as reported in Tylophora indica [14], Withania somnifera ${ }^{[15]}$ etc. Further there are reports supporting the embryogenic potential of leaf explants in Prunus mume ${ }^{[16]}$ and Solanum lycopersicum ${ }^{[17]}$. Proper explants selection is critical to achieve successful induction of somatic embryogenesis. There are several reports supporting the role of 2,4-D for somatic embryo initiation in Acacia catechu ${ }^{[18]}$ (Rout et al.,1993), Abelmoschus esculentus ${ }^{[19]}$ etc. Highest number of somatic embryos was induced from embryogenic calli in Holostemma adakodein on MS medium with lower concentration of 2,4-D. ${ }^{[20]}$ Similarly in our study lower concentration of 2,4-D along with coconut milk (40\%) produced maximum somatic embryo. Further the influence of cytokinin and auxin on embryo development and maturation have been reported in Carthamus tinctorius ${ }^{[21] .}$

However other workers reported multiple shoot regeneration from embryogenic calli in Eclipta alba. ${ }^{[22]}$ Our findings were also in the same line supporting the fact that auxin like NAA and cytokinin like BAP stimulates the embryogenic calli to develop multiple shoots. In our present investigation type II callus showed greenish yellow nodular structure as in case of Curculigo orchioides [23]. Different developmental stages of somatic embryo like globular, leaf primordials were evident from histological studies of leaf derived calli as in case of Phellodendron amurense ${ }^{[24]}$

Alginate is one of the common polymer used for production of synthetic seeds. It exhibits greater variation in viscosity, resulting in difficulty for decanting and encapsulation. In this view, several reports are published on enhanced germinability with lower alginate concentration (2-3\%) as in Centaurium rigualii ${ }^{[25] \text {, }}$ Eleusine coracana ${ }^{[26]}$ etc. Similar observations has been made in our study, lower concentration of alginate showed high rate of germination.

Storage of synthetic seed is a critical factor for exchange and preservation of germ plasm which determines the success of synthetic seed protocol. There are reports supporting higher conversion efficiency of synthetic seeds at cold $\left(4^{\circ} \mathrm{c}\right)$ storage as in Cleopatra tangerine ${ }^{[27]}$ applestock ${ }^{[28]}$ etc. A promising degree of interaction was observed between cold storage $\left(4^{\circ}\right)$ and storage interval up to 45 days for regrowth percentage as well as root and shoot development as reported in olive ${ }^{[29]}$. Contrarily the plantlets regenerated from room stored synthetic seeds, showed no much difference interaction between room temperature and storage interval. Contrarily non significant interaction between storage condition and storage interval was observed in room stored synthetic seed, exhibiting necrosis due to lack of quiescence and depletion of nutrition ${ }^{[30]}$. Further decline in germination percentage may be attributed due to inhibited respiration of somatic embryo by alginate bead ${ }^{[31] .}$ Similar line of interpretation hold good for our present investigation. 

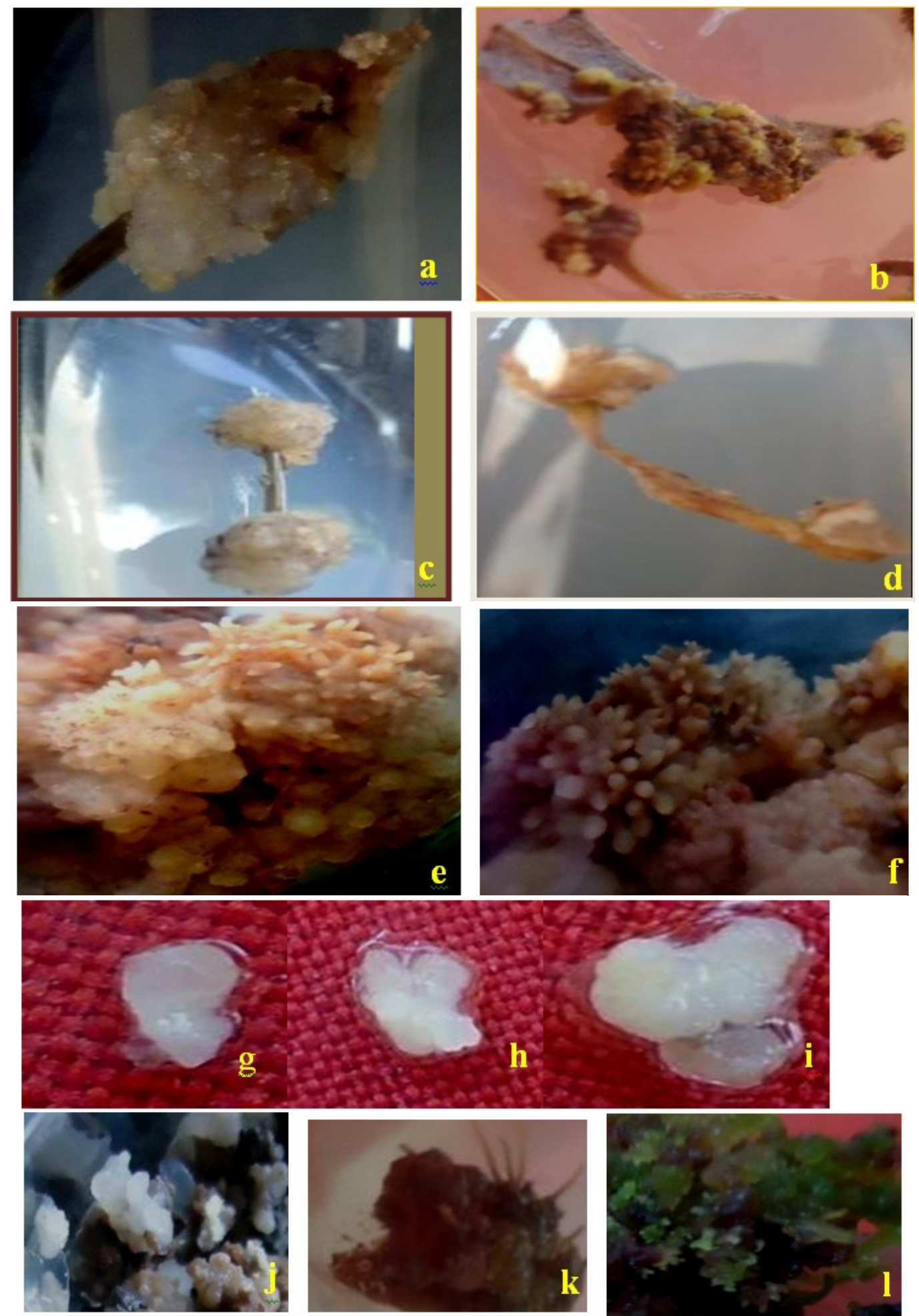

Fig 1 Callogenesis from different explants of Rumex vesicarius $L$ and Different stages of Somatic embryogenesis a-d: Callogenesis, e-l: Different stages of Somatic embryogenesis. a: Callus induction from node b:Callus induction from leaf c: Callus induction from internode $d$ : Callus induction from peduncle e, $\mathrm{f}$ : Induction of somatic embryos g: Globular embryo h: heart shaped embryo i: Torpedo shaped embryo j: cotyledonaty stage embryo k: rhizogenesis from somatic embryos $\mathrm{l}$ : germination of somatic embryos 

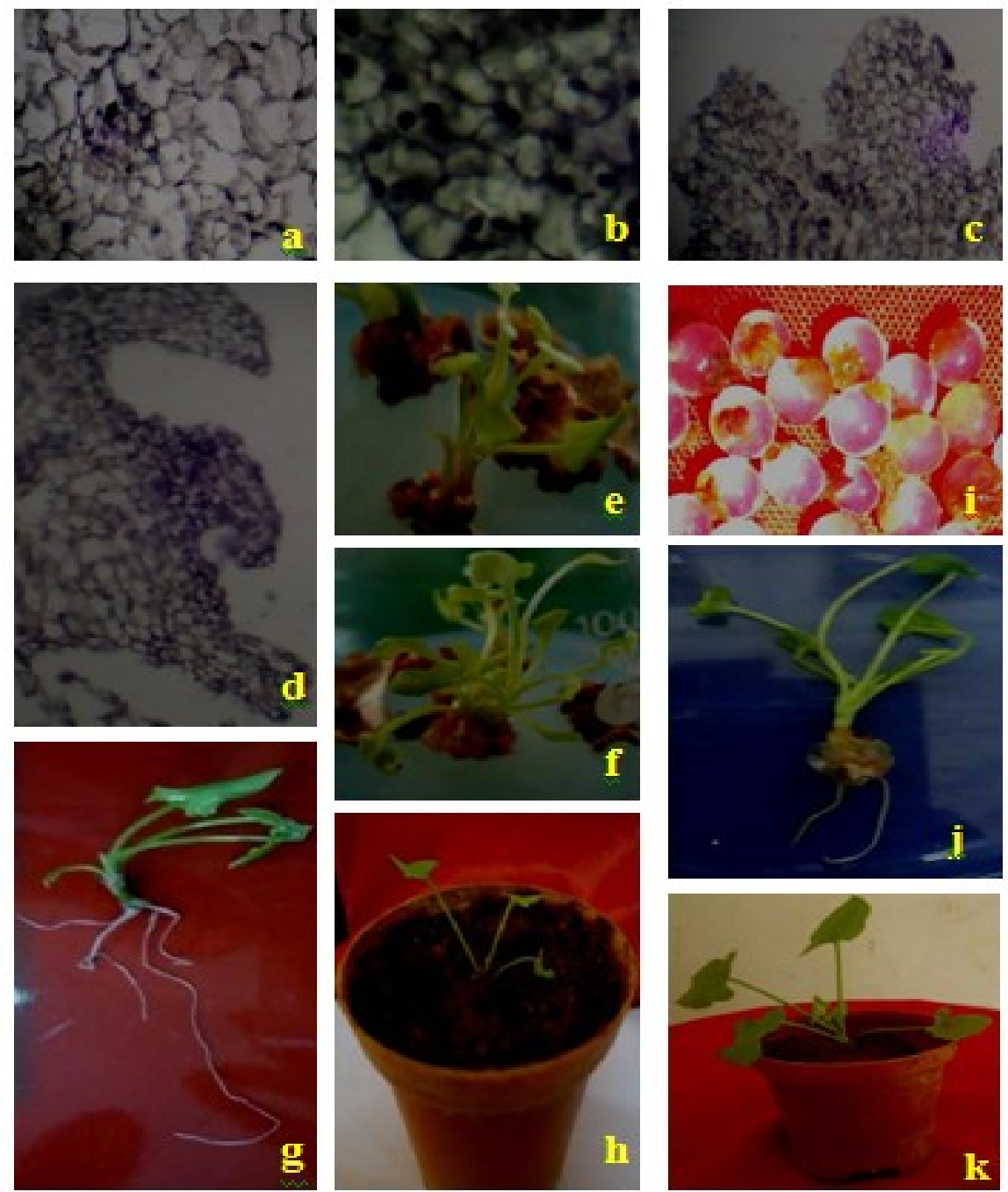

Fig 2: Regeneration of plantlets and germination of Synthetic seeds a-d:Histological stages; e-h - Regeneration of plantlets ; i-k: Production and germination of Synthetic seeds

a: Soft callus, b: Embryogenic callus, c: Section showing somatic embryos, d:Section showing differentiation of shoot bud, e: induction of multiple shoots from callus, f: Elongation of multiple shoots, g: Induction of rooting, $\mathbf{h}$ : Harden plant, $\mathbf{i}$ : encapsulation of somatic embryo; $\mathbf{j}$ : Germination of Synthetic seed; $\mathbf{k}$ : Accclimatized plant

Table-1: Effect of different concentrations of growth regulators on callus induction from different explants of Rumex vesicarius $\mathrm{L}$.

\begin{tabular}{|c|c|c|c|c|c|c|}
\hline \multirow[b]{2}{*}{ Explant } & \multirow{2}{*}{$\begin{array}{c}\text { Concentration } \\
(\mathrm{mg} / \mathrm{l})\end{array}$} & \multicolumn{2}{|c|}{ Individual } & \multirow{2}{*}{$\begin{array}{c}\text { Concentration } \\
(\mathrm{mg} / \mathrm{l})\end{array}$} & \multicolumn{2}{|c|}{ Combination } \\
\hline & & NAA & 2,4-D & & BAP+NAA & $2,4 \mathrm{D}+\mathrm{Kn}$ \\
\hline \multirow[t]{6}{*}{ Leaf } & 0.5 & $20.00 \pm 10.00$ & $40.00 \pm 0.00$ & $0.5+0.5$ & $40.00 \pm 10.00$ & $40.00 \pm 10.00$ \\
\hline & 1.0 & $30.00 \pm 10.00$ & $50.00 \pm 10.00$ & $1.0+0.5$ & $50.00 \pm 10.00$ & $50.00 \pm 10.00$ \\
\hline & 2.0 & $80.00 \pm 10.00$ & $80.00 \pm 10.00$ & $2.0+0.5$ & $70.00 \pm 10.00$ & $60.00 \pm 10.00$ \\
\hline & 3.0 & $70.00 \pm 10.00$ & $60.00 \pm 10.00$ & $3.0+0.5$ & $80.00 \pm 10.00$ & $70.00 \pm 10.00$ \\
\hline & Mean & 50.00 & $\mathbf{5 7 . 5 0}$ & Mean & 60.00 & 55.00 \\
\hline & $\mathrm{CD} @ 5 \%$ & 27.96 & 17.65 & $\mathrm{CD} @ 5 \%$ & 18.59 & 14.46 \\
\hline \multirow[t]{6}{*}{ Stem } & 0.5 & $10.00 \pm 5.00$ & $12.33 \pm 2.52$ & $0.5+0.5$ & $30.00 \pm 10.00$ & $16.67 \pm 7.64$ \\
\hline & 1.0 & $10.00 \pm 5.00$ & $30.00 \pm 5.00$ & $1.0+0.5$ & $33.33 \pm 5.77$ & $23.33 \pm 5.77$ \\
\hline & 2.0 & $40.00 \pm 15.00$ & $50.00 \pm 5.00$ & $2.0+0.5$ & $60.00 \pm 20.00$ & $40.00 \pm 10.00$ \\
\hline & 3.0 & $30.00 \pm 10.00$ & $30.00 \pm 10.00$ & $3.0+0.5$ & $46.67 \pm 11.55$ & $50.00 \pm 20.00$ \\
\hline & Mean & 22.50 & $\begin{array}{r}30.58 \\
\end{array}$ & Mean & 42.50 & 32.50 \\
\hline & CD@5\% & 15.88 & 14.91 & CD@5\% & 16.58 & 17.25 \\
\hline \multirow[t]{6}{*}{ Internode } & 0.5 & $10.00 \pm 5.00$ & $12.33 \pm 2.52$ & $0.5+0.5$ & $20.00 \pm 5.00$ & $10.00 \pm 5.00$ \\
\hline & 1.0 & $10.00 \pm 5.00$ & $20.00 \pm 10.00$ & $1.0+0.5$ & $20.00 \pm 5.00$ & $20.00 \pm 8.66$ \\
\hline & 2.0 & $33.33 \pm 10.41$ & $40.00 \pm 5.00$ & $2.0+0.5$ & $40.00 \pm 10.00$ & $40.00 \pm 15.00$ \\
\hline & 3.0 & $30.00 \pm 10.00$ & $30.00 \pm 10.00$ & $3.0+0.5$ & $50.00 \pm 10.00$ & $30.00 \pm 10.00$ \\
\hline & Mean & 20.83 & 25.58 & Mean & 32.50 & 25.00 \\
\hline & $\mathrm{CD} @ 5 \%$ & 13.29 & 12.67 & CD@5\% & 15.15 & 14.62 \\
\hline
\end{tabular}


Plant regeneration through somatic embryogenesis and synthetic seed production in Rumex

\begin{tabular}{|c|c|c|c|c|c|c|}
\hline \multirow[t]{3}{*}{ Peduncle } & $\begin{array}{l}0.5 \\
1.0 \\
2.0 \\
3.0 \\
\end{array}$ & $\begin{array}{c}10.00 \pm 5.00 \\
20.00 \pm 5.00 \\
50.00 \pm 20.00 \\
40.00 \pm 18.03 \\
\end{array}$ & $\begin{array}{c}13.33 \pm 2.89 \\
13.33 \pm 2.89 \\
40.00 \pm 15.00 \\
30.00 \pm 10.00 \\
\end{array}$ & $\begin{array}{l}0.5+0.5 \\
1.0+0.5 \\
2.0+0.5 \\
3.0+0.5 \\
\end{array}$ & $\begin{array}{l}20.00 \pm 13.23 \\
43.33 \pm \pm 7.64 \\
60.00 \pm 20.00 \\
50.00 \pm 13.23 \\
\end{array}$ & $\begin{array}{l}10.00 \pm 8.66 \\
20.00 \pm 5.00 \\
40.00 \pm 5.00 \\
30.00 \pm 5.00 \\
\end{array}$ \\
\hline & Mean & 30.00 & 24.17 & Mean & 43.33 & 25.00 \\
\hline & CD@5\% & 20.34 & 14.28 & CD@5\% & 19.58 & 12.79 \\
\hline \multirow[t]{4}{*}{ Overall } & $\begin{array}{l}0.5 \\
1.0 \\
\mathbf{2 . 0} \\
3.0\end{array}$ & $\begin{array}{c}12.50 \pm 7.23^{\mathrm{a}} \\
17.50 \pm 10.34^{\mathrm{a}} \\
50.83 \pm 22.34^{\mathrm{b}} \\
42.50 \pm 20.17^{\mathrm{b}}\end{array}$ & $\begin{array}{c}19.50 \pm 13.23^{\mathrm{a}} \\
28.33 \pm 15.86^{\mathrm{ab}} \\
52.50 \pm 19.01^{\mathrm{b}} \\
37.50 \pm 16.03^{\mathrm{c}}\end{array}$ & $\begin{array}{l}0.5+0.5 \\
1.0+0.5 \\
\mathbf{2 . 0}+\mathbf{0 . 5} \\
3.0+0.5\end{array}$ & $\begin{array}{l}27.50 \pm 12.15^{\mathrm{a}} \\
36.67 \pm 13.37^{\mathrm{a}} \\
57.50 \pm 17.65^{\mathrm{b}} \\
56.67 \pm 17.10^{\mathrm{b}}\end{array}$ & $\begin{array}{l}19.17 \pm 14.59^{\mathrm{a}} \\
28.33 \pm 14.67^{\mathrm{a}} \\
45.00 \pm 12.79^{\mathrm{b}} \\
45.00 \pm 20.34^{\mathrm{b}}\end{array}$ \\
\hline & Mean & 30.83 & 34.46 & Mean & 44.58 & 34.38 \\
\hline & $\mathrm{CD} @ 5 \%$ & 22.75 & 19.92 & CD@5\% & 19.70 & 19.01 \\
\hline & Sig & $\mathbf{S}$ & $\mathbf{S}$ & & $\mathbf{S}$ & $\mathbf{S}$ \\
\hline \multirow[t]{3}{*}{ F-Value } & Explant & 403.760 & 41.405 & & 11.733 & 24.702 \\
\hline & Concentration & 19.023 & 33.777 & & 20.099 & 20.163 \\
\hline & Interaction & 37.161 & .733 & & 1.095 & .759 \\
\hline
\end{tabular}

Note: Mean \pm Standard deviation followed by same superscript within a column are not significant when subjected to Tukey's mean range test at 0.05 level (CD-Critical Deviation)

Table 2: Effect of different concentrations of sodium alginate $(\%)$ and $\mathrm{CaCl} 2.2 \mathrm{H} 20(\mathrm{mM})$ on frequency of germination of encapsulated embryos on MS medium supplemented with BAP and NAA after two weeks of culture

\begin{tabular}{|c|c|c|c|c|}
\hline Alginate (\%) & \multicolumn{2}{|c|}{$\mathrm{CaCl}_{2}(\mathrm{mM})$} & Percent Germination & Germination days \\
\hline \multirow[t]{2}{*}{$2 \%$} & \multicolumn{2}{|l|}{100} & $85.00 \pm 5.00$ & $6.00 \pm 1.00$ \\
\hline & \multicolumn{2}{|l|}{125} & $80.00 \pm 10.00$ & $8.00 \pm 1.00$ \\
\hline \multirow[t]{2}{*}{$3 \%$} & \multicolumn{2}{|l|}{100} & $75.00 \pm 5.00$ & $9.00 \pm 1.00$ \\
\hline & \multicolumn{2}{|l|}{125} & $70.00 \pm 5.00$ & $10.00 \pm 1.00$ \\
\hline \multirow[t]{2}{*}{$4 \%$} & \multicolumn{2}{|l|}{100} & $65.00 \pm 5.00$ & $12.00 \pm 1.00$ \\
\hline & \multicolumn{2}{|l|}{125} & $60.00 \pm 10.00$ & $13.00 \pm 1.00$ \\
\hline \multirow[t]{5}{*}{ Overall } & \multirow[t]{2}{*}{$\mathrm{CaCl}_{2}$} & 100 & $75.00 \pm 9.68$ & $9.00 \pm 2.74$ \\
\hline & & 125 & $70.00 \pm 11.46$ & $10.33 \pm 2.35$ \\
\hline & \multirow[t]{3}{*}{ Alginate } & $2 \%$ & $82.50 \pm 7.58^{b}$ & $7.00 \pm 1.41^{\mathrm{a}}$ \\
\hline & & $3 \%$ & $72.50 \pm 5.24^{\mathrm{ab}}$ & $9.50 \pm 1.05^{b}$ \\
\hline & & $4 \%$ & $62.50 \pm 7.58^{\mathrm{a}}$ & $12.50 \pm 1.05^{\mathrm{c}}$ \\
\hline \multirow[t]{3}{*}{ F-Value } & \multicolumn{2}{|c|}{ Alginate (Conc.) } & 12.000 & 45.500 \\
\hline & \multicolumn{2}{|c|}{$\mathrm{CaCl}_{2}$ (Conc.) } & 2.250 & 8.000 \\
\hline & \multicolumn{2}{|c|}{ Alginate $\mathrm{Vs} \mathrm{CaCl}_{2}$ Interaction } & 0.000 & 0.500 \\
\hline
\end{tabular}

Table 3. Effect of different temperature and storage intervals on germination percentage (\%) of

\begin{tabular}{|l|l|l|l|}
\hline \multirow{2}{*}{ Storage interval } & \multicolumn{1}{|c|}{ Mean germination percentage $(\%)$} & \multirow{2}{*}{ Mean } \\
\cline { 2 - 4 } & \multicolumn{1}{|c|}{ Cold storage $\left(\mathbf{4}^{\circ} \mathbf{C}\right)$} & Room storage $\left(\mathbf{2 1} \pm \mathbf{2}^{\circ} \mathbf{C}\right)$ & \\
\hline S0 ( 0 days) & $60.00 \pm 10.00$ & $65.00 \pm 5.00$ & $62.50^{\text {ab }}$ \\
\hline S1 (15 days) & $70.00 \pm 10.00$ & $70.00 \pm 10.00$ & $70.00^{\text {ab }}$ \\
\hline S2 (30 days) & $80.00 \pm 10.00$ & $65.00 \pm 5.00$ & $72.50^{\mathrm{b}}$ \\
\hline S3 (45 days) & $85.00 \pm 5.00$ & $70.00 \pm 10.00$ & $77.50^{\mathrm{b}}$ \\
\hline S4 (60 days) & $60.00 \pm 10.00$ & $50.00 \pm 10.00$ & $55.00^{\mathrm{a}}$ \\
\hline Mean & $\mathbf{7 1 . 0 0}$ & $\mathbf{6 4 . 0 0}$ & \\
\hline F-Value & 6.048 (Storage Interval) & 4.742 (Temperature) & $1.597($ Interaction) \\
\hline
\end{tabular}

Note: Mean \pm Standard deviation followed by same superscript within a column are not significant when subjected to Tukey's mean range test at 0.05 level (CD-Critical Deviation) 


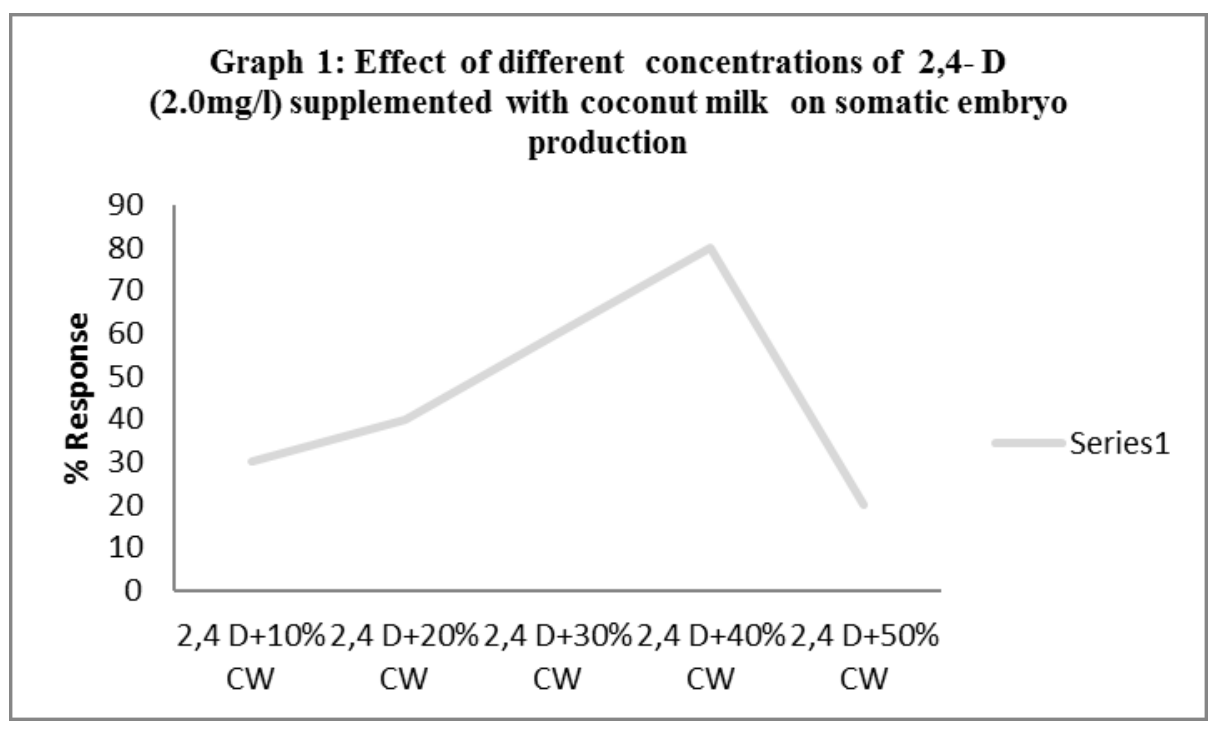

\section{Conclusion}

Indiscriminate usage of Rumex vesicarius for various medicinal preparations might lead to threaten or endangered state. Hence, the established protocol of high frequency of embryogenic calli for regeneration of plants, multiple shoot and synthetic seed production provides a platform for mass multiplication of plants and to conserve the germ plasm from the natural habitat. It also provides plant material for further usage and research studies.

\section{Acknowledgements}

The authors are thankful to Institute of Excellence, University of Mysore for providing the financial assistance and Department of Studies in Botany for providing the necessary facilities to carry out this research work.

\section{References}

[1]. AA. Elegami, AZ. Almagboul, MAO. El faith, MS. El Tohami. Sudanese plants used in folkloric medicine: Screening for antibacterial activity. Part X. Fitoterapia. 2001; 72:810-817.

[2]. S. Al-Quran. Ethnopharmacological survey of wild medicinal plants in Showbak, Jordan. J Ethnopharmacol. 2009; 123:4550 .

[3]. HAM. Mostafa, AA. EL-Bakry, EA. Alam. Evaluation of antibacterial activity of different plant parts of Rumex vesicarius L. at early and late vegetative stages of growth. Int. J. Pharm. Pharm. Sci. 2012; 4:426-435

[4]. AA. Asrar. Seed germination induction of Hommaidh (Rumex vesicarius L.) by gibberlic acid and temperature applications. Am Eurasian J Agric Environ Sci. 2011;10(3):310-317.

[5]. VC.Pence. The application of biotechnology for the conservation of endangered plants. In: Benson EE (Ed) Plant conservation biotechnology. Taylor \& Francis, London, 1999; 227-241

[6]. AK. Sahrawat and S.Chand. Somatic embryogenesis and plant regeneration from root segments of Psoralea corylifolia L., an endangered medicinally important plant. In vitro Cell. Dev.biol- Plant. 2002; 38:33-38.

[7]. AA. Tawfik, G. Noga. Cumin regeneration from seedling derived embryogenic callus in response to amended kinetin. Plant Cell Tiss Org. Cult. 2002; 69: 35-40

[8]. B.Roy, AB. Mandal. Development of synthetic seed involving androgenic and proembryos in elite indica rice, Indian $\mathrm{J}$ Biotech. 2008; 7: 515-519

[9]. SA. Bekheet. A synthetic seed method through encapsulation of in vitro proliferated bulblets of garlic (Allium sativum L). Arab J Biotech. 2006; 9:415-426.

[10]. Z. Latif, A. Idrees, A.Nasir, S. Riazuddin. Indigenous production of synthetic seeds in Daucus carota. Pak J Bot. 2007;39: 849855

[11]. Y. Anand, YB. Bansal. Synthetic seed: a noval approach of in vitro plantlet formation in Vasaka (Adhatoda vasica Nees). Plant Mol.2002; 19:159-162

[12]. T. Murashige, F. Skoog. A revised medium for rapid growth and bioassay with tobacco tissue culture. Physiol. Plant.1962 ; 15: 473497.

[13]. DA. Johansen, Plant Microtechnique. Mc Graw Hill Book Co; New York. 1940;523.

[14]. M. Faisal, M, Anis. An efficient in vitro method for mass propagation of Tylophora indica. Biol plantarum. 2003; 49: 257-260.

[15]. G. Rani, GS.Virk, A. Nagpal. Callus induction and plantlet regeneration in Withania somnifera (L.) Dunal. In vitro Cell. Dev.biol. Plant. 2003; 39: 468-474.

[16]. Guo gui ning, Xiao li fan, Wen jun huang, Man zhu bao and Jin bo zhang. Micropropagation of six prunus mume cultivars through axillary shoot proliferation and issr analysis of cloned plants . Acta biol cracov bot. 2007;49/1:25-31,

[17]. Godishala Vikram, Kairamkonda Madhusudhan, Kagithoju Srikanth, Mangamoori Laxminarasu and Nanna Rama Swamy. Effect of plant growth regulators on in vitro organogenesis in cultivated tomato. J Res Biol. 2011; 4: 263-268.

[18]. GR. Rout, S. Samantaray, P. Das. Somatic Embryogenesis and plant regeneration from callus cultures of Acacia catechu - a multipurpose leguminous tree. Plant Cell. Tiss. Org. Cult. 1993; 4:238-245. 
[19]. SA. Haider, R. Islam, AHM. Kamal, SM. Rahman, OI. Joarder. Direct and indirect organogenesis in cultured hypocotyl explants of Abelmoschus esculentus (L.) Moench. - Plant Tissue Cult. 1993; 3:85-89.

[20]. KP. Martin. Plant regeneration through somatic embryogenesis on Holostemma ada-kodien, a rare medicinal plant. Plant Cell Tiss. Organ Cult. 2003; 72(1): 79-82.

[21]. SP. Kumar, BDR. Kumari. Factors affecting on somatic embryogenesis of safflower (Carthamus tinctorius L.) at morphological and biochemical levels. World J Agric Sci. 2011; 7: 197-205.

[22]. P. Baskaran, N. Jayabalan. An efficient micro propagation system for Eclipta alba - a valuable medicinal herb. In vitro Cell. Dev.biol - Plant. 2005; 41:532-539

[23]. KS, Nagesh, C, Shanthamma, T. Pullaiah. Somatic embryogenesis and plant regeneration from callus cultures of Curculigo orchioides. Indian J biotech. 2010; 9: 408-413.

[24]. Mustafa Abdul Kalam Azad, Shinso Yokota, Futoshi Ishiguri, Shoji Yahara, Nobuo Yoshizawa. Histological studies of shoot regeneration system in hypocotyls derived callus of Phellodendron amurense Rupr. J for Res. 2005;10: 377-384

[25]. MEG Benito, C Perez, AB, Viviani. Cryopreservation of nodal explants of an endangered plant species (Centaurium rigualii Esteve) using the encapsulation-dehydration method. Biodivers and conserve. 1992; 6: 583-590.

[26]. George Leela and Eapen Susan. Encapsulation of somatic embryos of finger millet, Eleusine coracana Gaertn. Indian J Exp Biol. 1995; 33: 291.

[27]. N. Nieves, JC. Lorenzo, MA. Blanco, J. Gonzalez, H. Peralta, M. Hernandez, R. Santos. O. Concepcion, CG, Borroto, E. Borroto, R.Tapia, ME. Martinez, Z. Fundora, A. Gonzalez. Artificial endosperm of Cleopatra tangerine zygotic embryos: A model for somatic embryo encapsulation. Plant Cell Tiss Org. Cult. 1998;54: 77-83.

[28]. M. Sicurani, E. Piccioni, A. Standardi. Micropropagation and preparation of synthetic seed in M. 26 apple stock I: attempts towards saving labour in the production of adventitious shoot tips suitable for encapsulation. Plant Cell Tiss. Organ Cult. 2001; 66:207-216.

[29]. M. Ikhlaq, IA. Hafiz, M.Micheli, T.Ahmad - In vitro storage of synthetic seeds: Effect of different storage conditions and intervals on their conversion ability Afr J Biotechnol, 2010;9(35):5712-5721.

[30]. N. Nieves, Y. Zambrano, R.Tapia, Cid M, Pina D and R. Castillo. Field performance of artificial seed derived sugarcane plants. Plant Cell Tiss. Organ Cult. 2003; 75: 279-282.

[31]. K. Redenbaugh, D. Slade, P. Viss, JA. Fuji. Encapsulation of somatic embryos in synthetic seed coats. J hortic sci. 1987; 22:803809. 